\title{
Políticas públicas de educação, a formação dos professores e a instrução pública no período de 1946- 1971: Escola Estadual Dom Orione (Curitiba/PR)
}

Public education policies, teacher education and public education during 1946-1971: Dom Orione State School (Curitiba/PR) Politicas públicas de educación, la formación de los profesores y la instrucción pública em el período de 1946 1971: Escuela Estadual Dom Orione (Curitiba/PR)

MARIA ElisABeth BLANCK Miguel (iDa

\section{Resumo}

Este artigo trata da relação entre as políticas públicas de educação, a formação dos professores e a instrução pública em Curitiba/PR. Neste texto, focaliza-se uma das instituições pesquisadas, a Escola Estadual Dom Orione, no período 1946-1971, segundo os documentos escolares e o testemunho dos professores que a vivenciaram. Para levantar as fontes e selecioná-las utilizou-se a metodologia histórico-documental. Foram levantados documentos escolares do acervo da instituição pesquisada e coletados depoimentos de professores que vivenciaram as propostas no período. A análise dos conteúdos fundamentou-se em Araújo (2012), Carvalho (1989), Souza (2015, 2009), Bloch (2001), Ciavatta (2007), Mira et al. (2017) e Padis (2006). Como resultado da pesquisa é possível afirmar que os dados indicam forte importância da gestão escolar nas

\footnotetext{
a Pontifícia Universidade Católica do Paraná (PUCPR), Curitiba, Paraná, Brasil. Doutora em História e Filosofia da Educação, e-mail: maria.elisabeth@pucpr.br.
} 
adequações vividas pela escola. Tal importância foi observada nos documentos, imagens e testemunho dos participantes da investigação. A passagem da instituição de orientação confessional para escola pública teve a presença da igreja mesmo após a escola haver passado para a gestão do estado. A aplicação das legislações referentes ao período não foi percebida pelos testemunhos, levantando a hipótese de que tais políticas não foram implantadas de imediato. O bom êxito do ensino na vida dos estudantes foi comprovado porque muitos, após a conclusão dos cursos, direcionaram-se à Escola Técnica de Curitiba, hoje Universidade Federal Tecnológica do Paraná, demonstrando resultados positivos. A tríade: estado, igreja e família foi um fator muito elogiado pelos professores, assim como a direção da escola.

Palavras-chave: Políticas Públicas. História da Educação do Paraná. Escola Estadual Dom Orione.

\section{Abstract}

This article is about the relation between public education policies, teacher education and public education in Curitiba, Parana. This article focuses on one of the researched institutions, Dom Orione State School, in the period of 1946-1971, as stated by the school documents and the testimony of the teaches of the time. In order to gather information and select them, the historical-documentary methodology was used. School documents were collected from there searched institution's records and statements were gathered from teachers who experienced the changes during the period. The content analysis was based on Araújo (2012), Carvalho (1989), Souza (2015, 2009), Bloch (2001) and Padis (2006). With the results of the research, it is possible to affirm that the data indicates the school management had strong importance in the adaptations lived by the school. Such importance was observed in the documents, images, and testimony of the participants. The transition from a confessional-oriented institution to a public school was attended by the church even after the school was managed by the state. The legislation applied during the time period was not noticed by the testimonies, raising the hypothesis that such policies were not implemented immediately. The education's success in the lives of students has been proven because many, after completing the courses, turned to Technical School of Curitiba, nowadays Federal University of Technology of Parana, showing positive results. The triad between State, Church, and Family was highly praised by teachers, as was the school board.

Keywords: Public Policies. Educational History of Parana. Dom Orione State School.

\section{Resumen}

Este artículo aborda la relación entre las políticas públicas de la educación, la formación de los profesores y la instrucción pública, en Curitiba/PR y se enfoca la Escuela Estadual Dom Orione, em el período 1946-1971, según los documentos escolares y el testimonio de los profesores que la experimentaron. Para recoger las fuentes y seleccionarlas se utilizó la metodología histórico-documental: documentos escolares de la colección de la institución 
investigada y recogidos, testimonios de profesores que experimentaron las propuestas em el período. El análisis se fundamento en Araújo (2012), Carvalho (1989), Souza (2015, 2009), Bloch (2001) y Padis (2006). Como resultados de la investigación, es posible afirmar que los datos indican la importancia de la gestión escolar em las adaptaciones experimentadas por la escuela. Tal importancia fue observada em los documentos, imágenes y testimonios de los participantes de la investigación. El paso de la institución de orientación confesional para la escuela pública tuvo la presencia de la iglesia, aún después de la escuela Haber pasado para la gestión del estado. La aplicación de la legislación referente al período no fue percibida por los testimonios, levantando se la hipótesis de que estas políticas no fueron implantadas de inmediato. El buen éxito de la enseñanza em la vida de los Estudiantes fue comprobada porque muchos, después de concluídos los cursos se direccionaron al Escuela Técnica de Curitiba, hoy Universidad Federal Tecnológica de Paraná. La tríade: Estado, Iglesia y Familia fue un factor muy elogiado por los profesores, tal y como la dirección de la escuela.

Palabras clave: Políticas Públicas. Historia de la Educación de Paraná. "Escuela Estadual Dom Orione".

\section{Introdução}

Este trabalho trata da relação entre as políticas públicas de educação, a formação dos professores e a instrução pública no Paraná no período 1946-1971.

Das instituições pesquisadas, tomamos como exemplo a Escola Estadual Dom Orione localizada em Curitiba. A investigação que sustenta este artigo teve ainda como objetivos específicos: identificar as influências das políticas nacionais sobre as políticas estaduais de educação no período da passagem da Lei 4024/61 para a vigência da Lei 5692/71; identificar como os professores sentiram a influência das políticas nacionais e estaduais sobre suas práticas no período estudado e como se deu a implantação das propostas então veiculadas em âmbito nacional, na Escola Estadual Dom Orione.

Além desses objetivos, também há o interesse dos pesquisadores em preservar a memória das instituições de ensino, a partir do momento no qual o governo do Paraná anunciou em 2015 a intenção de encerrar as atividades de algumas escolas estaduais que representam relevante legado para a história da educação do estado.

A escola pode ser considerada como um dos "lugares de memória", como conceituou Nora (1984 apud CIAVATTA, 2005), embora, como bem nos faz lembrar Ciavatta (2005, p. 11): 
Por ser um espaço ocupado pela infância e a juventude, cujo sentimento do passado é quase inexistente, a escola (que não é citada pelo historiador) parece ser um lugar de memória ainda mais esmaecido. No entanto, esse sentimento aflora com o passar do tempo e até a vivência com os colegas de infância e de juventude tornam-se, mais tarde, densos 'lugares de memória', contribuindo para a construção de uma identidade singular e, ao mesmo tempo, coletiva, como pertencimento a um tempo, a um grupo com as marcas desse tempo.

Explorando esse lugar de memória, como bem podemos considerar a escola, e lembrando Nora (1984, p. 9 apud CIAVAT'TA 2005, p. 1) para quem a "memória se enraíza no concreto, no espaço, no gesto, na imagem e no objeto", buscamos levantar fontes documentais e colher testemunhos daqueles que participaram da vida escolar no período escolhido para a pesquisa.

A investigação histórica contou com o levantamento de fontes que se distinguem em sua natureza, isto é, documentos oficiais que imprimem o discurso empregado por parte do poder público no sentido das orientações quanto ao campo educacional do período e documentos escolares, que registram o modo como tais orientações foram implementadas no cotidiano do funcionamento institucional, além de testemunhos de professores que vivenciaram tais propostas em sua atuação profissional.

A escolha por realizar tais procedimentos é justificada na tentativa de aproximar-se do que Bloch (2001) afirma sobre a coleta de fontes históricas:

Como primeira característica, o conhecimento de todos os fatos humanos no passado, da maior parte deles no presente, deve ser, [segundo a feliz expressão de François Simiand,] um conhecimento através de vestígios (BLOCH, 2001, p. 73).

Assim, consideramos as fontes colhidas e as informações que as mesmas registram como vestígios da história vivida na escola. Essas foram analisadas à luz do referencial teórico de Araújo (2012) que trata do surgimento dos primeiros grupos escolares em Escola primária na primeira república (1889-1930); Carvalho (1989) na obra A escola e a república; Souza, Pinheiro e Lopes (2015), que tratam da História da escola primária no Brasil; Souza (2009) na obra Alicerces da Pátria: história da escola primária no estado de São Paulo (1890-1976); Ciavatta (2005, 2007) em A formação integrada: a escola e o trabalho como lugares de memória e de identidade e em Memória e temporalidade do trabalho e 
educação quando conceitua a fotografia como fonte histórica; Nora (1993 apud CIAVATTA 2005) ao tratar dos "lugares de memória", no texto Entre a memória e a história: a problemática dos lugares. Ainda, Bloch (2001),ao abordar o método de investigação histórica, no livro Apologia da história ou o ofício do historiador, Padis (2006) na obra Formação de uma economia periférica: o caso do Paraná.

Além dos referidos autores, foram consultadas as edições da Revista Brasileira de Estudos Pedagógicos (DUTRA, 1946; MIRA et al., 2017) e a Revista do Ensino (1972) cujo número publicou o documento-base da reforma de ensino implantada pela Lei 5692/71, com o título de "Articulação e Integração no Ensino de $1^{\circ}$ Grau" no Paraná, tratando das diretrizes teóricas dos currículos de $5^{\mathrm{a}}$ e $6^{\mathrm{a}}$ séries. Ainda foram consultadas as legislações educacionais pertinentes: Lei Orgânica do Ensino Primário (1946), Lei de Diretrizes e Bases da Educação Nacional 4024/61, Lei Estadual 4978 de 05 de dezembro de 1964, que adequou o Sistema de Ensino do Paraná à LDB e a Lei $5692 / 71$.

Para ampliar a compreensão das decisões e projetos do período no contexto brasileiro e paranaense, fez-se necessário levantar o contexto sócio-político, cultural e econômico do estado no período pesquisado, pois como afirma Bloch (2001, p. 31):

[...] numa sociedade, qualquer que seja, tudo se liga e se controla mutuamente: a estrutura política e social, a economia, as crenças, tanto as manifestações mais elementares como as mais sutis da mentalidade.

A seguir, foram trabalhadas as informações das fontes escritas encontradas na instituição escolar e após as entrevistas. Estas aconteceram nas dependências da universidade e também via contato telefônico, conforme disponibilidade de cada participante.

Tomou-se como ponto de partida o período provincial, ou seja, quando a Paraná ainda pertencia à Província de São Paulo enquanto $5^{a}$ Comarca, pois a partir de então a educação escolar passou a ser considerada a "mola propulsora para o progresso", segundo Carvalho (1989). Foi então identificado nos Relatórios da Instrução Pública, provenientes dos inspetores, que o professor era considerado elemento central para o bom êxito da educação ou das políticas públicas educacionais. 
A formação do professor continuou a ser apontada como fator de sucesso da escolarização dos alunos no período republicano.

Nesta pesquisa, os questionamentos pertinentes a esse período se fazem no sentido de compreender como se deu a implantação das legislações na escola, como esta passou de confessional para pública e como os professores vivenciaram tais mudanças no cotidiano escolar. Pois,

Consideramos que toda mudança na política educacional que visa a alguma alteração no contexto escolar precisa levar em conta a forma como as propostas se materializam no chão da escola, na medida em que a implementação depende muito da cultura profissional existente nesse contexto, ou seja, quem são e como pensam e agem os professores e os demais profissionais que ali atuam (MIRA et al.,2017, p. 666).

\section{O contexto mais amplo do período}

As primeiras décadas republicanas foram marcadas por preocupações em relação à educação primária, superação das políticas regionais e educação modernizadora ${ }^{1}$ segundo Araújo, Souza e Pinto (2012), como enfrentamento aos altos índices de analfabetismo populacional somado às disparidades regionais de ensino em diferentes realidades no período.

Foram realizadas reformas estaduais para adequar a realidade educacional ao projeto de educação que progressivamente se aproximava da relação entre trabalho e escola, tendo em vista que esse serviço seria oferecido para cidadãos de uma nova sociedade, isto é, uma sociedade que já não se sustentava pela mão de obra escrava.

[...] a República brasileira buscou imprimir um sentido modernizador às suas ações, através do investimento em reformas estaduais, implementadas ao final do século XIX e primeiras décadas do século XX (ibid., p. 333).

As reformas são importantes para compreender o contexto, mas não serão aprofundadas neste trabalho, pois foge ao objetivo proposto para esta discussão. No entanto, cabe citá-las

${ }^{1}$ Modernização, segundo os autores, é compreendida como adoção das agendas educacionais e do vocabulário pedagógico das nações civilizadas (países centro-europeus e, com maior destaque, Estados Unidos da América) (ARAúJO; SOUZA; PINTO, 2012, p. 333). 
$\mathrm{Na} 1^{\text {a }}$ República ocorreram reformas nacionais; a Reforma Benjamin Constant (1890) que defendia o ensino leigo e livre, sendo o ensino primário gratuito. Este, para Constant, "não deveria apenas ser preparatório, mas uma ponte para a ascensão ao ensino superior” (BOMENY, 2015, p. 4). Reforma Epitácio Pessoa (1901) que favoreceria a concretização dos ideais de Benjamin Constant, "corrigindo e adaptando a reforma deste às realidades regionais" (BOMENY, 2015, p. 5).

A Reforma Rivadávia Correia (1911) revogou as orientações realizadas pela reforma Epitácio Pessoa. Em razão desta reforma “o Estado retirou toda e qualquer interferência no setor educacional” (BOMENY, 2015, p. 6). Reforma Carlos Maximiliano (1915) também retirou a vigência de grande quantidade de orientações feitas em relação à reforma Rivadávia Correia, além de estabelecer novos encaminhamentos. Esta reforma oficializou novamente o ensino.

A escola, no centro do debate que envolvia o desenvolvimento da nação em relação à economia e à ocupação do meio rural e urbano, com "expectativas quanto a uma distribuição 'racional' da população pelas atividades rurais e urbanas" (CARVALHO, 1989, p. 65) era compreendida enquanto:

[...] espécie de antídoto largamente receitado contra o 'congestionamento das cidades' e 'o pauperismo urbano com seus perniciosos efeitos'. Quanto à escola adaptada ao meio urbano, era comum a expectativa de que viesse 'combater, ou pelo menos atenuar em seus efeitos morais, essa vida tumultuosa, corrosiva, ávida de prazeres' com os recursos oferecidos pela moderna pedagogia (CARVALHO, 1989, p. 65).

No período pós-30, no entanto, os governos estaduais "não deixaram de reclamar a participação da União na expansão da oferta educacional elementar" destacando "a insuficiência de rendas para arcar com as demandas e necessidades escolares das unidades federativas" (SOUZA, 2015, p. 77).

Ainda, segundo a mesma autora, foi a partir da década de 1940 que o governo federal assumiu, efetivamente, postura de colaboração junto às unidades federativas e com municípios para ampliação da rede escolar primária em suas zonas rurais e urbanas.

Cabe destacar, nesse período, que as iniciativas religiosas e privadas ainda eram frequentes, justamente pelo embate de concepções educacionais vigentes entre setores distintos da sociedade. Mesmo após a República haver proclamado o Estado 
brasileiro como laico, a disputa por espaços, pela vertente católica, não cessou, inclusive no campo educacional. Em 1949, o então presidente da República, Eurico Gaspar Dutra, quando em seu Plano de educação assim se pronunciou:

A toda criança residente no Brasil será, pois, dada obrigatoriamente, a partir dos sete anos de idade, em organização didática oficial ou particular, a educação fundamental comum, mas em condições de lhe assegurar continuação aos cuidados do ensino profissional, nos graus elementar e médio, de acordo com a aptidão revelada. Essa educação será gratuita no ensino do Estado (DUTRA, 1946, p. 9).

Segundo a Revista Brasileira de Estudos Pedagógicos (1946), tratava-se de um período de fortes encargos à educação popular, fomento de oportunidades na conquista dos conhecimentos e técnicas de produção, e na aquisição de atitudes e valores que elevassem o indivíduo e a vida social. Tais direcionamentos foram mantidos pela Lei de Diretrizes e Bases da Educação Nacional de 1961.

É na década de 1940 que surge a instituição escolar de orientação católica no bairro de Santa Quitéria em Curitiba/PR.

\section{Santa Quitéria: uma visão do conjunto}

A região onde atualmente se situa o bairro Santa Quitéria, localizado na cidade de Curitiba, inicialmente era "uma extensa lavoura de milho, feijão, arroz e outros cereais"(IPPUC, 2015) com grande disparidade de desenvolvimento econômico em relação às regiões vizinhas de Campo Comprido, Vila Izabel e Portão.

O relato histórico registra a tentativa de nomear a região com o nome de "Carmela Dutra”, em homenagem à esposa do presidente da República, Eurico Gaspar Dutra. Para os moradores, no entanto, permaneceu o nome Santa Quitéria, em alusão à imagem da santa doada à capela da cidade por Dona Maria Bitana, moradora do bairro.

Segundo a prefeitura de Curitiba, o progresso daquela região se deu a partir do grande contingente populacional que o "programa Caixa de Habitação Popular”(1965), posteriormente, substituído pelo Banco Nacional de Habitação $(\mathrm{BNH})$, incentivou quando "construiu centenas de casas que foram compradas por funcionários públicos”(CURITIBA, 2013, s/p) em 1950; junto à “união e o sentido de 
vida comunitária de sua população" (CURITIBA, 2013, s/p)de acordo com os registros oficiais.

Conforme ocorreu o povoamento da área, foi fundada a Sociedade Beneficente e Recreativa de Santa Quitéria em 1949. Sob o objetivo de atender crianças com deficiências, foi instalado o primeiro pavilhão do Pequeno Cotolengo do Paraná, anexado à igreja de Santa Quitéria em 1971. Observou-se também o registro de incidência de trabalhos de cunho social da Congregação da Pequena Obra da Divina Providência, quando do interesse dos padres Orionitas em se instalarem no bairro mais pobre de Curitiba:

Quando os padres orionitas se ofereceram a algum trabalho na cidade, fizeram questão de pedir ao arcebispo o bairro mais pobre da cidade. 'Mais pobre que Santa Quitéria não existe em Curitiba, por isso é lá que preciso de vocês! ' afirmou sem titubear o arcebispo. E eis que a missão foi aceita. (ORIONITAS, s/d, s/p).

Ainda, a instalação dos Orionitas e o desenvolvimento da região acompanharam o movimento posterior à intensa atividade agroprodutora das décadas de 1940 e 1950, sendo o decênio dos anos 1960 relatado por autores como um período:

[...] marcado por ingentes esforços governamentais: inter alia, devem ser destacados aqueles que se dirigiram à suspensão das deficiências infra-estruturais e à criação de condições e estímulos à implantação industrial (PADIS, 2006, p. 261).

O movimento econômico no qual estava inserida a Congregação da Pequena Obra da Divina Providência levou-a a criar uma escola com a finalidade de ofertar à população, atendimento educacional e formativo. Os princípios dos padres Orionitas foram decisivos para o desenvolvimento do bairro, não somente em relação ao espaço escolar, mas também junto a outras instituições.

Destaca-se ainda, a importante noção de vida comunitária compartilhada pelos moradores do bairro Santa Quitéria, potencializando tal desenvolvimento. Assim, tomou forma e se consolidou a atual Escola Estadual Dom Orione. 


\section{Escola Estadual Dom Orione}

Essa escola está localizada no bairro Santa Quitéria, em Curitiba, e passou a funcionar como instituição pública de ensino em 1967. Antes, porém, pertencia à Ordem dos Padres da Divina Providência; sua criação, conforme está registrado nos documentos escolares deu-se pela intenção de atender os filhos dos operários que moravam nas proximidades da Paróquia de Santa Quitéria, local que abrigaria a escola em prédio anexo. Em 1973 foram implantadas as $2^{\mathrm{a}}, 3^{\mathrm{a}}$ e $5^{\mathrm{a}}$ séries do $1^{\mathrm{o}} \mathrm{grau}$, em observação à lei 5692/71.

A pesquisa permitiu compreender como funcionou essa escola, quais os pontos relevantes de sua atuação e como as leis foram ou não, aplicadas naquele espaço escolar. Os resultados encontrados contribuíram para uma melhor aproximação do problema central de pesquisa, na medida em que os materiais do período escolhido foram disponibilizados pela direção da escola, e assim, possibilitaram aprofundar a compreensão das transformações e adequações pelas quais passou a instituição, principalmente a partir da promulgação da LDB 4024/61. Esta foi a base da Lei 4978 de 05 de dezembro de 1964 que estabeleceu o sistema estadual de ensino do Paraná (PARANÁ, 1964).

Procurando verificar se os testemunhos dos professores que atuaram na escola, participaram das mudanças exigidas pela legislação, buscou-se o contato com eles. Os nomes foram obtidos ao consultarmos o livro ponto de então. A seguir foi feita uma busca por telefone ou pela internet. Alguns foram localizados e a eles foi exposta a pesquisa, bem como os objetivos dela e a importância da contribuição para o conhecimento da relação entre as leis e as práticas escolares desenvolvidas, pois:

[...]podemos considerar que há uma relação dialética entre políticas educacionais expressas na legislação e as práticas cotidianas (costumes, cultura) e, nesse caso, práticas escolares: as práticas vão gradativamente sendo alteradas em função da legislação, mas esta também sofre influência das práticas existentes, na medida em que as pessoas agem sobre a realidade (Thompson, 1988). Desse modo, a legislação pode trazer pistas ou indícios de práticas que podem ser implementadas no decorrer do tempo, embora a forma como cada sociedade lida com a lei seja distinta. Da mesma forma, as experiências individuais e coletivas são apropriadas e reelaboradas considerando a legislação (MIRAet al., 2017, p. 666.) 
Assim, a participante A relatou que não lembrava como foram as adaptações da escola às mudanças exigidas pelas legislações. Segundo ela, a escola se localizava em uma região de difícil acesso, especialmente em períodos de chuva, pois era um cenário de "banhado" e mesmo o transporte por ônibus tornava-se difícil.

Em consideração às dificuldades, o número de professores que se interessava em desenvolver suas atividades naquela instituição era significativamente reduzido. Em razão disso, aqueles que atuavam na escola Dom Orione observavam que a direção se esforçava em valorizar seus trabalhos. Segundo seu testemunho:

\begin{abstract}
A diretora [...] nos acolheu muito bem e depois, quando saiu o concurso, ela dava assim: vinte aulas para cada professor, para criar um vínculo; porque ninguém iria até lá por cinco aulas, dez aulas. Então ela [a diretora] dava o máximo que podia. Quando saiu o concurso, eu me formei em 69, acho que o concurso saiu entre 70 e 71, ela tinha muitos professores que fariam o concurso. Então, ela sentou e nos fez uma proposta: se nós puséssemos o padrão lá, que era de 10 aulas; se nós puséssemos o padrão lá, ela nos daria as aulas extras que nós poderíamos dar até um total de 30 .
\end{abstract}

Desse modo, a direção tinha a preocupação em favorecer os professores na participação da vida escolar. Havia o interesse por parte dela em formar um corpo docente com identidade institucional, capaz de aderir à concepção, cultura e funcionamento da escola.

Os relatos das testemunhas trouxeram um dado importante referente ao "apadrinhamento" que professores realizavam em relação aos alunos. Por tratar-se de uma região economicamente pouco desenvolvida no período, as características financeiras dos alunos indicavam necessidades básicas. Segundo a participante A, a diretora:

[...]fazia com que, dependendo do perfil, [...] cada professor apadrinhasse uma turma, no sentido de zelar, de ver quem estava passando fome, de ver quem vinha maltrapilho, quem faltava demais, porque era uma região de favela. Era uma região que os alunos chegavam imundos e cadê a lição? - Professora, a cabra comeu meu caderno, respondiam[...] Então a gente tinha uma turma que a gente era padrinho ou madrinha daquela turma, ela [diretora] fazia com que tudo funcionasse.

Quando questionada sobre sua percepção na transição dessa escola que era de ordem confessional para instituição pública, a participante afirmou não ter sentido isso durante seu período de atuação (1966-1975), pois se afastou de suas atividades no período de 1972-1974 por motivos pessoais. 
Segundo seu relato, a presença da Congregação "permaneceu muito forte" dentro da escola e na comunidade em razão de um trabalho social significativo, havendo, inclusive, professoras freiras na instituição. Embora tenha afirmado não se recordar muito bem como se deram as adequações administrativas das legislações no cotidiano escolar, relatou que tais decisões não eram trabalhadas nas reuniões pedagógicas, as quais eram utilizadas para informar somente das decisões pedagógicas.

Em outro testemunho, a participante B relata que trabalhou muito tempo na escola, mas não soube precisar o período. Informou sobre sua apreciação em relação à gestão composta pela igreja, estado e família. Essa organização da gestão era o diferencial, segundo a participante, que garantia à escola assistir os alunos de modo diferenciado. Destacou, em especial, passeios que eram realizados com os alunos nas indústrias próximas à escola, principalmente à Companhia de Energia Elétrica do Paraná (Copel). A participante B ainda citou sua admiração pela eficiência do preparo escolar ofertado aos alunos, pois um número significativo de estudantes que terminava seus estudos na Escola Estadual Dom Orione ingressava na Escola Técnica de Curitiba, hoje Universidade Federal Tecnológica do Paraná ${ }^{2}$. Os alunos direcionavam-se então a uma carreira profissional.

A instituição realizava também passeios escolares, atividade desenvolvida não somente pela escola citada, mas também por muitas outras no período; os passeios foram definidos por autores como uma alternativa pedagógica para aprendizagem da própria vida em comunidade.

O passeio educativo era antes de tudo uma atividade escolar, um meio, uma oportunidade, mais uma alternativa para favorecer o desenvolvimento infantil e transmitir conhecimentos, normas, valores às crianças. Justificava-se assim, a exigência de protocolos de observação, a disciplinarização do olhar e do interesse das crianças - o que ver, o que investigar, o que descobrir (SOUZA, 2009, p. 238).

Verifica-se a importância de atividades dessa natureza em relação à formação do aluno, uma vez que complementava o ensino recebido dentro da instituição escolar junto à aquisição de conhecimentos.

2 Sobre o histórico da Universidade Federal Tecnológica do Paraná, consultar: https://pt.wikipedia.org/wiki/Universidade_Tecnol\%C3\%B3gica_Federal_do_Paran\%C3\%A1.

Acesso em: 12 dez. 2019. 
A participante $C$ informou que trabalhou durante seis meses na instituição, mas não soube precisar o período. Reservou-se unicamente a se queixar dos alunos, caracterizando-os como terríveis.

As participantes B e C também não se lembraram do modo como sentiram a mudança da escola confessional para escola pública, bem como suas percepções em relação às influências das políticas de educação na escola e consequente implantação. Ciavatta (2005) aponta Michel Pollack como um autor que trata com propriedade o tema da memória e do esquecimento na construção da identidade dos grupos, auxiliando-nos a compreender os esquecimentos de fatos que, para nós, teriam sido importantes na vida da escola. Segundo ela, o autor

[...] analisa diversos grupos sociais e as 'memórias subterrâneas' ou marginalizadas, e como estas memórias competem na consolidação de uma história, de uma versão, do papel de um determinado grupo social, na preservação ou no esquecimento de certos fatos e de seus significados (CIAVATTA, 2005, p.12).

Segundo a participante A, quando questionada sobre a implantação das legislações, informou que a instituição demorou a implantar as orientações da lei 5692/71, pois o exame de admissão ainda era vigente no período em que lá esteve (até 1975).

A partir da Lei 5692/71, as escolas deveriam oferecer oito anos de escolaridade enquanto educação de $1^{\circ}$ grau, excluindo o exame de admissão. Os professores passaram a trabalhar em função de objetivos comportamentais, nos níveis intelectual, afetivo e psicomotor, seguindo a Taxionomia de Bloom, segundo as Diretrizes teóricas dos currículos de $5^{\mathrm{a}}$ e $6^{\mathrm{a}}$ séries do ensino de $1^{\mathrm{o}}$ grau, que constam do documento da Secretaria de Educação e Cultura do Estado do Paraná, intitulado “Articulação e Integração no Ensino de $1^{\circ}$ Grau”, publicado na Revista do Ensino (1972):

Objetivos comportamentais são aqueles que descrevem as espécies de comportamento que são buscados nos alunos, enquanto estes freqüentam a instituição escolar. Benjamin Bloom, em 'Taxionomia dos objetivos educacionais, formula um esquema de classificação dos objetivos e os coloca em três domínios: 1-Domínio cognitivo [...]; 2- Domínio afetivo [...]; Domínio psico-motor [...]. (REVISTA DO ENSINO, 1972, p.14-15). 
Embora as testemunhas não lembrem ou desconheçam o modo como foram implantadas as orientações das leis na escola, dentre os documentos que indicam essa adequação, foi encontrado um arquivo datilografado (Figura 1) na biblioteca escolar com a denominação: caracterização da instituição.

Tal dado histórico revela o percurso resumido da instituição assim como as devidas alterações realizadas em seu funcionamento durante os períodos, principalmente referentes à abertura do terceiro turno.

Figura 1 - Documento de caracterização da instituição

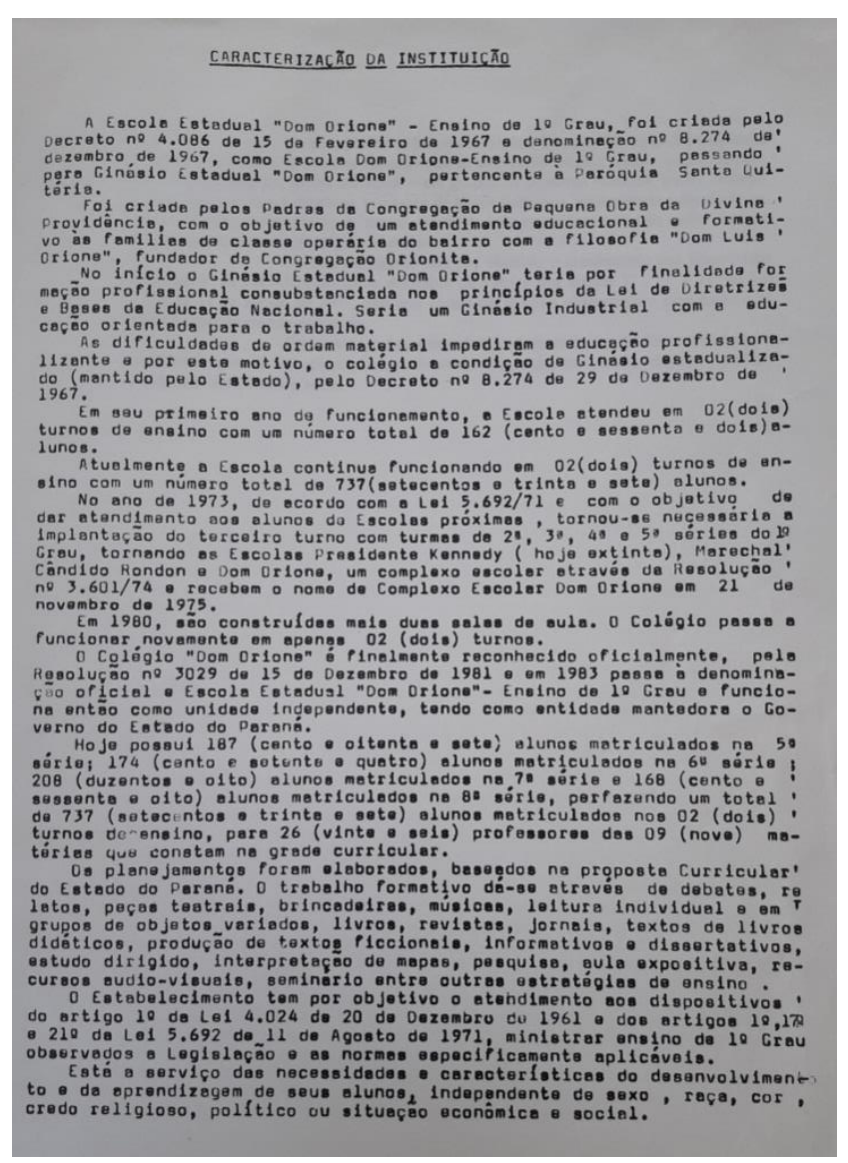

Fonte: acervo escolar da Escola Estadual Dom Orione (2019).

O documento registra o histórico da instituição na década de 1980, indicando haver sido elaborado em um período posterior ao referenciado. Nele encontram-se informações que atualmente integram as que estão relacionadas à escola no site da Secretaria de Estado de Educação do Paraná (SEED-PR).

Foram encontrados outros documentos relativos à caracterização da instituição com conteúdo similar, atualizado, cuja única mudança está em seu último 
parágrafo indicando a organização de cargos, seguido da frase "A juventude será o sol ou a tempestade do amanhã", conforme se observa a seguir:

Figura 2 - Documento recente sobre de caracterização da instituição

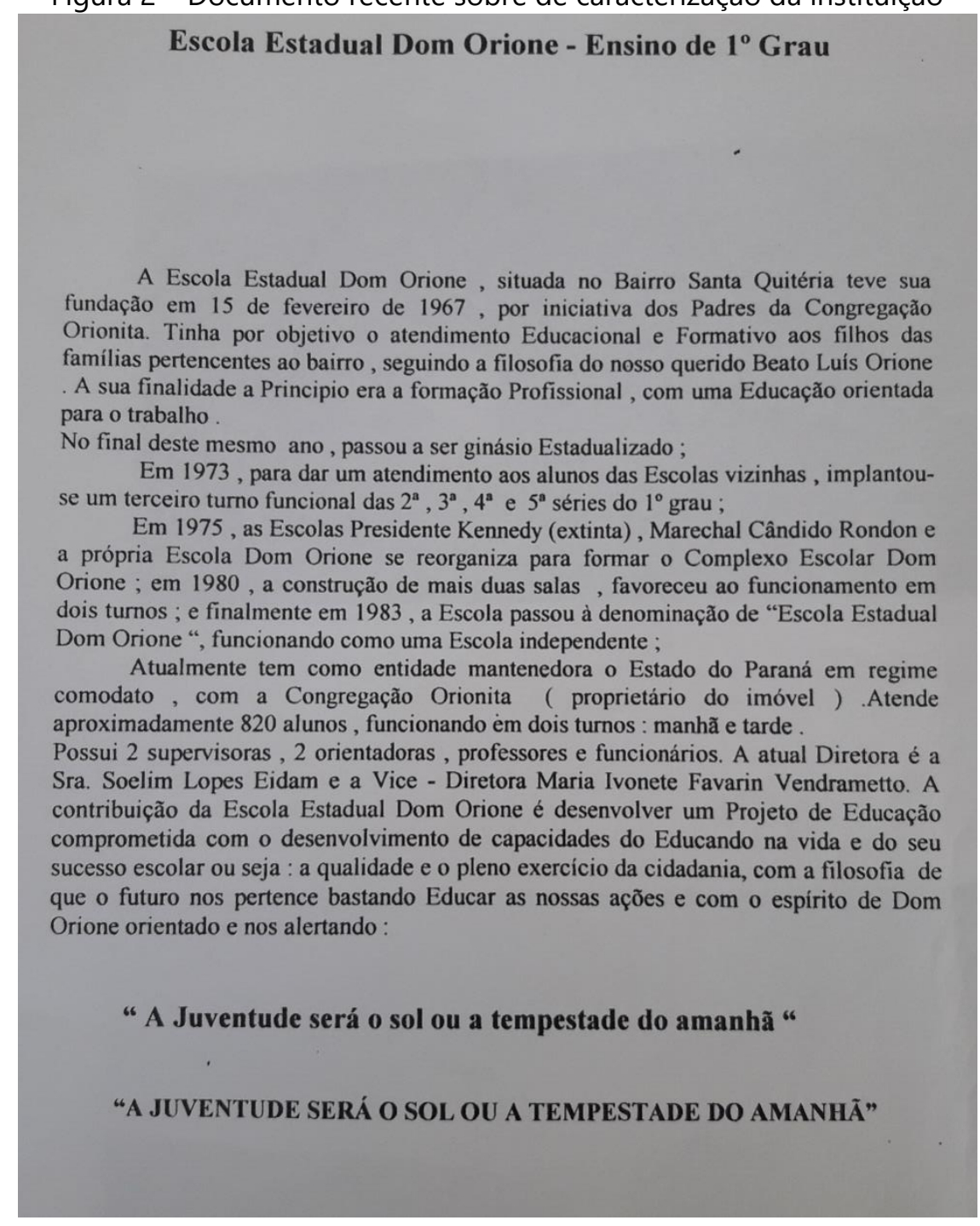

Fonte: acervo escolar da Escola Estadual Dom Orione (2019)

Embora o documento não indique a data de publicação, constata-se sua atualidade devido ao reconhecimento de nomes e cargos ainda vigentes na escola.

Também as fotografias que constam do arquivo escolar serviram de fontes para a investigação. Maria Ciavatta (2007, p. 35), em sua obra intitulada Memória e temporalidades do trabalho e da educação, afirma que "o pesquisador se utiliza desta fonte para recuperar os vínculos da fotografia com os momentos históricos”.

Toda fotografia é um resíduo do passado. Um artefato que contém em si um quadro determinado da realidade registrado fotograficamente. Se, por um lado, este artefato nos 
oferece indícios quanto aos elementos constitutivos (assunto, fotógrafo, tecnologia) que Ihe deram origem, por outro, o registro visual nele contido reúne um inventário de informações daquele precioso fragmento de espaço/tempo retratado. $O$ artefato no seu todo, assim como o registro visual na sua individualidade, constitui uma fonte histórica (KOSSOY, 1989, p. 30-31 apud CIAVATTA, 2007, p. 35).

Também a mesma pesquisadora em outro artigo já havia afirmado que:

Documentos dispersos, preservados na história particular de muitos, fotografias, livros, papéis e objetos guardados com zelo e nostalgia podem alimentar a perspectiva de uma escola e de uma formação integrada e mais completa para os mais jovens, em reconhecimento e orgulho de si mesmos como mestres (CIAVATTA, 2005, p. 14).

No sentido de colher as informações que a fotografia enquanto uma fonte histórica transmite é certificar-se que elas foram consultadas.

Foram encontradas imagens de estudantes e corpo docente de diferentes períodos, onde foi possível observar o registro da integração entre a comunidade escolar, principalmente nas fotos que registram o almoço comemorativo aos 20 anos da fundação da escola com a presença da $1^{a}$ turma e professores.

Nos documentos consultados, ainda foram encontradas muitas imagens que registram passeios do corpo docente e dos estudantes, ratificando de tal modo o testemunho da participante B.

Verifica-se, em observação às fotografias, que mesmo após a conclusão do ciclo de estudos pelos alunos, aqueles que residiam no entorno da escola aparecem em muitos dos registros fotográficos de comemoração da instituição. Esses foram identificados pela diretora atual.

Em outra fotografia (Figura 3) os estudantes praticavam atividades físicas durante a aula de Educação Física, que ocorre no campo de areia da escola, com o detalhe da Igreja de Santa Quitéria ao fundo. 
Figura 3 - Registro da aula de Educação Física

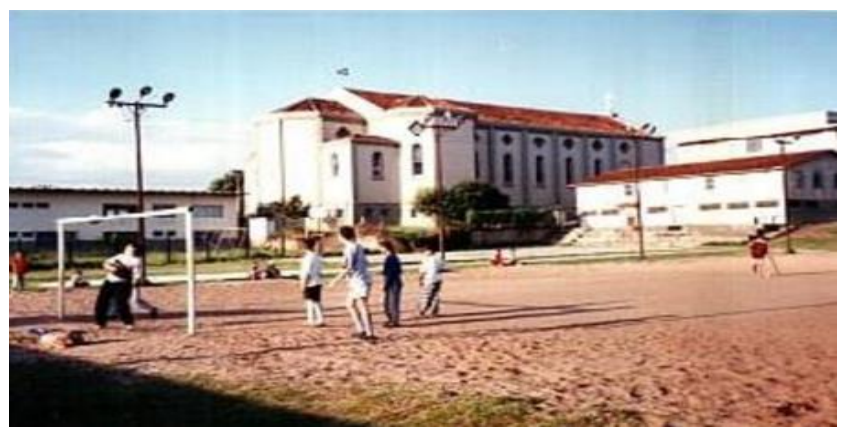

Fonte: acervo escolar da Escola Estadual Dom Orione (2019)

Atualmente, no lugar do campo de areia, há uma quadra poliesportiva com cobertura que foi construída pelo estado, para que os estudantes pratiquem suas atividades nas aulas de Educação Física com melhores condições.

Em outra foto que mostra o interior de uma sala de aula, vê-se uma cruz ao centro, na parte superior e a imagem de uma figura cristã, no lado esquerdo do quadro.

A religião esteve presente nas leis da educação brasileira, embora facultativa aos estudantes, após a República. No entanto as imagens registradas nas fotos, bem como os registros dos documentos e o testemunho dos professores entrevistados, mostram que ela fez parte das práticas escolares das escolas públicas brasileiras. Seguindo a Lei de Diretrizes e Bases da Educação de 1961, a Lei Estadual 49783, de 05 de dezembro de 1964, estabelecia no Artigo 18, do Capítulo III, que tratava da organização do ensino:

Art. 18. O ensino religioso, no sistema estadual de ensino, constitui disciplina dos horários das escolas oficiais e é de matrícula facultativa; será ministrado de acôrdo com a confissão religiosa do aluno, manifestada por êle, se fôr capaz, ou pelo seu representante legal ou responsável.

$1^{\circ}$. A formação de classe para o ensino religioso independe de número mínimo de alunos. $2^{\circ}$. O registro dos professôres do ensino religioso será realizado perante a autoridade religiosa respectiva;

$3^{\circ}$. Os estabelecimentos de ensino público estaduais são obrigados a assegurar, na organização dos currículos e horários, pelo menos uma hora de aula semanal de ensino religioso, de freqüência obrigatória para os alunos inscritos. (PARANÁ, 1964, p. 4) 
Observou-se, ainda, a disciplina como uma característica dessa instituição de ensino, pois é registrada em grande número de fotografias. A disciplina escolar, também presente no quotidiano, acompanhou a educação dos alunos que frequentaram escolas públicas no período pesquisado.

\section{Considerações finais}

A Escola Estadual Dom Orione foi criada por uma iniciativa religiosa com a intenção de contribuir para a superação da realidade econômica de um bairro relativamente pouco desenvolvido na metade do século XX por meio de uma educação formativa. O projeto era ambicioso, porém os recursos eram limitados.

O público alvo, filhos dos operários, logo ocupou os assentos escolares e a Congregação Orionita, então mantenedora da instituição, deparou-se com a necessidade de aumentar seus recursos para viabilizar o projeto educacional, momento no qual o governo do estado do Paraná assumiu a escola enquanto agente mantenedor.

Inicialmente atuando como Seminário e escola de ordem confessional, logo passou a ser escola pública, aumentando a oferta de vagas, e se transformando no Grupo Escolar Dom Orione. Muitos de seus alunos obtiveram resultados de seus esforços, pois ingressaram na Escola Técnica de Curitiba, hoje Universidade Tecnológica Federal do Paraná (UTFPR), direcionando-se para uma carreira profissional.

A busca cada vez maior por vagas na instituição, segundo os professores que lá atuaram, refletia seu ensino eficiente, com valores definidos e com resultados positivos. Junto à sua criação enquanto escola pública, no final da década de 1960, adequou-se às implantações da Lei de Diretrizes e Bases da Educação (BRASIL, 1961). Com isso os desafios para alcançar os objetivos iniciais do projeto tornaramse mais complexos.

A alta demanda de alunos na região pressionou a escola a abrir um novo turno de funcionamento. E a Congregação Orionitanão podia mais influenciar nas decisões 
da escola, embora a Paróquia de Santa Quitéria ficasse em prédio anexo ao pavilhão escolar.

Quando direcionamos questionamentos aos participantes da pesquisa, isto é, aos professores que atuaram no período de 1946 a 1971 na instituição, emergiram de suas memórias relatos positivos e negativos, que nos auxiliaram a articular as informações contidas nas fontes encontradas com os fatos narrados pelos testemunhos.

A tríade: estado, igreja e família foi um aspecto lembrado positivamente na gestão escolar, principalmente em decorrência da proximidade dos professores com os seus alunos e que lhes permitia conhecê-los em suas necessidades e realidades (apadrinhamento).

As participantes não souberam informar como decorreu a passagem da orientação confessional para escola pública, afirmando que a igreja continuou muito presente no cotidiano escolar, justamente por desenvolver trabalho social na região, buscando atender problemas ocasionados pela grande vulnerabilidade econômica e social dos alunos, aspectos salientados por uma delas.

Em depoimentos de professores que vivenciaram as propostas na época foi identificado que não se lembram da passagem de escola de orientação confessional para pública, isto é, laica. De fato, a alteração não se caracterizou de forma clara na escola, uma vez que muitos elementos religiosos permaneceram presentes e a própria igreja ainda tinha influência dentro daquele espaço, havendo o relato de professoras freiras atuando naquele momento.

Esse fato é comprovado pelas fotografias coletadas no próprio acervo escolar e também foi mencionado por parte dos testemunhos quando da orientação religiosa em datas ou momentos especiais na escola. Nos documentos encontrados, apesar de se referirem à instituição enquanto escola pública, e que, portanto, segundo a lei deveria ser laica, foram constatados elementos religiosos presentes na sala de aula e um espaço reservado à homenagem a Dom Orione. Informaram também que, eventualmente, eram rezadas missas em datas especiais.

A influência das políticas nacionais e estaduais na escola não foi percebida pelas participantes da pesquisa. É possível que tais políticas não tenham sido implantadas de imediato e, portanto, essa seja a razão das professoras não se 
recordarem de como ocorreu esse processo. A abertura do terceiro turno (noturno) pela instituição era fato desconhecido por uma das participantes. De acordo com os documentos, esse turno passou a ser ofertado a partir do ano de 1973, momento em que a professora ainda atuava na escola. Segundo seu relato, nas reuniões pedagógicas não eram passadas informações em relação às adequações administrativas exigidas pelo texto da Lei; as informações eram todas de cunho pedagógico.

A reconstrução histórica, a partir dos dados coletados, permitiu identificar o papel da gestão escolar enquanto forte influenciador do bom funcionamento da instituição. As testemunhas informaram o apreço pela gestão e o bom ensino prestado pela escola, preparando bem o aluno para sua vida.

É possível afirmar que o objetivo inicial da criação da escola foi atingido, quando observada sua trajetória até o momento, pelo impacto na vida de seus alunos e no desenvolvimento do bairro Santa Quitéria. Os professores relatam que esses continuaram os estudos e lograram profissão na sociedade, resultado de um processo educacional básico eficiente.

Os elementos coletados não fornecem informações suficientes para que se possa afirmar com exatidão se a políticas públicas de educação foram implantadas a bem do ensino, fornecendo espaço para a suposição de que essas políticas não tenham sido implantadas de imediato no cotidiano escolar. É possível compreender que as escolas não conseguiram implantar de pronto as modificações exigidas pela Lei $5692 / 71$, principalmente porque o então ensino primário passou a ser articulado ao ginasial, compondo o ensino do $1^{\circ}$ grau com oito anos de escolaridade obrigatória.

Todavia, a amostra de participantes foi especialmente reduzida em razão da disponibilidade de testemunhas. Ainda assim, os testemunhos coletados contribuem para a compreensão histórica que a gestão escolar desempenhou e das dificuldades de implantação das políticas educacionais.

As práticas pedagógicas, os passeios realizados, a proximidade da comunidade escolar com a família e a igreja também contribuíram para o bom êxito e resultados colhidos pela instituição.

O trabalho de pesquisa foi relevante para a preservação da memória da escola e das suas fontes, assim como dos testemunhos, pois elas (fontes) foram encaminhadas para o Museu da Escola do Paraná, órgão da Secretaria de Estado da 
Educação do Paraná. Acreditamos também que, além de responder aos objetivos da pesquisa a que nos propusemos, contribuímos para a preservação da memória da educação paranaense.

\section{Referências}

ARAÚJO, José Carlos Souza; SOUZA, Rosa Fátima de; PINTO, Rubia-Mar Nunes. Escola primária na primeira república (1889-1930): subsídios para uma história comparada. 1. ed. Araraquara : Junqueira \& Marin, 2012.

BLOCH, Marc. Apologia da história on oficio do historiador. Rio de Janeiro: Zahar. 2001.

BOMENY, Helena. Reformas Educacionais. CPDOC, Fundação Getúlio Vargas. 2015. Disponível em: https://cpdoc.fgv.br/sites/default/files/verbetes/primeirarepublica/REFORMAS\%20EDUCACIONAIS\%20.pdf. Acesso em: 01 set. 2019.

BRASIL, Presidência da República. Lei 5692, 11 de agosto de 1971. Fixa as Diretrizes e Bases para o ensino de $1^{\circ}$ e $2^{\circ}$ graus, e dá outras providências.Brasília: Casa Civil. Disponível em: http://www.planalto.gov.br/ccvil_03/leis/L5692.htm. Acesso em: 01 set. 2019.

BRASIL. Presidência da República. Lei 4014, 20 de dezembro de 1961. Fixa as Diretrizes e Bases para o ensino de $1^{\circ}$ e $2^{\circ}$ graus, e dá outras providências.Brasília: Casa Civil. Disponível em: http://www.planalto.gov.br/ccivil_03/leis/L4024.htm. Acesso em: 01 set 2019.

CARVALHO, Marta Maria Chagas de. A Escola e a República. 1. ed. São Paulo: Brasiliense, 1989.

CIAVATTA, Maria (org.). Memória e temporalidades do trabalho e educação.Rio de Janeiro: Faperj: Lamparina Editora, 2007.

CIAVATTA, Maria. A Formação Integrada: a escola e o trabalho como lugares de memória e de identidade. Trabalho Necessário, Niterói, ano 3, n. 3, 2005. Disponível em: http://periodicos.uff.br/trabalhonecessario/article/view/6122.Acesso em: 11 nov. 2019.

CURITIBA. Francisco Pereira de Macedo e o Bairro Santa Quitéria. Câmara Municipal de Curitiba.2013. Disponível em: http://www.cmc.pr.gov.br/ass_det.php?not=20532. Acesso em: 01 set. 2019.

DUTRA, Eurico Gaspar. Educação Primária. Revista Brasileira de Estudos Pedagógicos,v. 7, n. 16, p. 9 , $1946 . \quad$ Disponível em: http://rbep.inep.gov.br/index.php/rbep/article/view/1381/1292. Acesso em: 01 set. 2019.

IPPUC. Instituto de Pesquisa e Planejamento Urbano de Curitiba. NossoBairro: Santa Quitéria.2015. Disponível em:http://www.ippuc.org.br/nossobairro/anexos/43Santa\%20Quit\%C3\%A9ria.pdf. Acesso em: 01 set. 2019.

MIRA, Marilia Marques; AKSENEN. Elisângela Zarpelon; CASTEX, Lilian Costa; MICHALOVICZ, Cátia Corrêa. Edward P. Tompson e a pesquisa em educação: a formação de professores em questão. Revista Brasileira de Estudos Pedagógicos, Brasilia, v. 98, n. 250, p. 
657-671, set./dez. 2017. Disponível em:http://dx.doi.org/10.24109/21766681.rbep.98i250.2975. Acesso em: 08 ago. 2019.

ORIONITAS. Orionita em Curitiba: sempre juntos ao povo. Disponível em: http://www.orionitas.com.br/destaques_orionitas_santa_quiteria.ph. Acesso em: 01 set. 2019.

PADIS, Pedro Calil. Formação de uma economia periférica: o caso do Paraná: O Paraná: Uma visão de Conjunto. Curitiba: Ipardes, 2006.

PARANÁ, Casa Civil. Lei 4978, de 05 de dezembro de 1964. Estabelece o sistema estadual de ensino. Paraná: Diário Oficial, 1964. Disponível em: http://www.legislacao.pr.gov.br/legislacao/pesquisarAto.do?action=exibir\&codAto $=1235$ 0\&coItemAto134377. Acesso em: 01 set. 2019.

PARANÁ. Projeto Político Pedagógico. Escola Estadual Dom Orione, 2011. Disponível em: http://www.ctadomorione.seed.pr.gov.br/redeescola/escolas/9/690/4490/arquivos/File/ PPP.pdf. Acesso em: 01 set. 2019

REVISTA DO ENSINO. São Paulo; Porto Alegre: Secretaria do Estado do Rio Grande do Sul, Edições Tabajara, n. 147, suplemento especial n. 4, 1972.

SOUZA, Rosa Fátima de; PINHEIRO, Antonio Carlos Ferreira; LOPES, Antônio de Pádua Carvalho. História da escola primária no Brasil: investigação em perspectiva comparada em âmbito nacional. 1. ed. Aracaju: Edise, 2015.

SOUZA, Rosa Fátima de. Alicerces da Pátria: história da escola primária no estado de São Paulo (1890-1976). Campinas: Mercado de Letras, 2009. 